International Journal of Engineering \& Technology, $7(3.27)(2018) 192-195$
International Journal of Engineering \& Technology
WPC
Website: www.sciencepubco.com/index.php/IJET
Research paper

\title{
Opinion Mining Embedding with Applications to Opinions
}

\author{
Pavani $^{1}$, U.V. Anbazhagu ${ }^{2 *}$, Bhavadharani ${ }^{3}$, M. Latha ${ }^{4}$, J. Senthil $^{5}$ \\ ${ }^{1}$ Student, Department of CSE, Vels University, Chennai. \\ ${ }^{2}$ Assistant Professor, Department of CSE, Vels University, Chennai.E-mail:Anbazhagu.se.@velsuniv.ac.in \\ ${ }^{3}$ Student, Department of CSE, Vels University, Chennai.E-mail:bhavadharani08@gmail.com \\ ${ }^{4}$ Assistant Professor, Department of CSE, Vels University, Chennai. \\ ${ }^{5}$ Assistant Professor, Department of CSE, Vels University, Chennai. \\ *Corresponding authorE-mail: anbazhagu.se@velsuniv.ac.in @ gmail.com
}

\begin{abstract}
The main objective of this project, we portray strategies to consequently create and score another estimation vocabulary, called sentimental analysis. Sentimental analysis is the one of the real errands of machine learning processing. Individuals post their own emotions and contemplating any items for an internet business website, (for example, Amazon, Flip card etc).sometime individuals needs to know whether these posts are positive, negative or unbiased. Existing word inserting learning calculations regularly just utilize the settings of words yet disregard the assumption of writings. Now we are applying enclose to word level assumption and stepwise level supposition arrangement, and estimation vocabularies. Information utilized as a part of this study are online item data sets are gathered from amazon.com. Experiments for both sentence-level and word-level are performed.
\end{abstract}

Keywords: Opinion mining, sentimental analysis, item surveys, machine learning.

\section{Introduction}

Sentiment is a state of mind, thought, or judgment incited by feeling. Sentimental analysis also knows as opinion mining. Ponders individuals' suppositions towards certain elements. Web is a creative place as for estimation data. From a customer's view, others can tag their own substance through another social media networking, discussions, minor scale browser journals, or media long range interpersonal speech level points. Be that as it may, those kinds of media document have a few imperfections that probably ruining the access for assessment checking. In this the principal will inform that the individuals can openly give their own content, and then their sentiments won't be published. In this instance, other than the point same insights, media hackers post spam on meetings. Many spams are good for nothing by any means, and others have various feelings called sentiments.

The next defect on the ground truth like such media data isn't generally accessible.Datasets that has ground truth and is additionally open accessible. The corpus contains 1.6 million machine-labelled Twitter messages. Each message is labelled in light of the emotions (as Positive, as negative) found inside the message.

Table 1: Feedback Table

\begin{tabular}{|l|l|}
\hline Star Level & General Meaning \\
\hline & I hate it. \\
\hline & I don't like it. \\
\hline & It's okay. \\
\hline
\end{tabular}

\section{Background}

Feeling examination and assessment mining because of its social and e-business esteem has turned into an exceptionally hot subject of research nowadays. On other hand on the web online networking has turned into a most critical method of correspondence on Web 2.0. Consequently opinion investigation what's more, client sentiment mining on online web-based social networking has extraordinary social and business significance. On social media for supposition investigation twitter due to is effortlessness has stayed essential focal point of analysts. Consequently in this proposed to dissect e-commerce posts and remarks for conclusions and opinions of the open. Methodologies utilized as a part of writing for sentimental analysis and sentiment mining are basically in view of three composes which incorporate machine learning, Lexicon and hybrid.

Machine learning based approaches for the most part utilize administered learning where a bit of content contrasted and human created rundown of opinion bearing word. In this approach a general scores (pretty much positive, negative or nonpartisan) is allocated to the content in light of the human outlined rundown. This strategy works better for short casual content where individuals are less formal in utilizing language structure, which is the situation in the general population remarks on the ecommerce. 


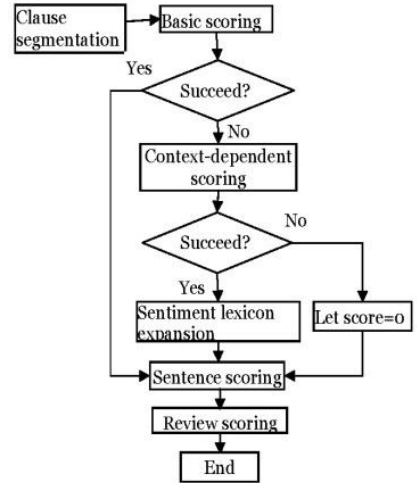

Figure 1: Sentimental analysis process

Second sort of methods depend on appropriate linguistic beware of the content utilizing different strategies for Natural Language Processing. These methods are required for content where legitimate language has been utilized. At last, Hybrid procedures utilize mix of previously mentioned and related methods for assumption investigation and supposition mining. For instance in a half and half method of supposition digging for online business applications is proposed which is a mix of essential part investigation for highlight diminishment and managed machine learning for expectation of suppositions.

\section{Methodology}

Opinion investigation is the way toward recognizing whether a lump of content conveys positive, negative or natural emotions. People have their characteristic capacity to discover feelings. Human based slant examination and feeling mining bears a few constraints portrayed as takes after

- Un-adaptable

- Can devour colossal measure of time

- Un-reasonable for constant basic leadership

- Extremely tedious

- Might be conflicting if surveyed by various human

Keeping in mind the end goal to manage this restriction of people, a computational system for assumption examination and sentiment mining is proposed, in this work. Primary stream and usefulness of the proposed structure. Sentences of the content records are broken into its Parts of Speech (POS), which distinguishes the components of a record contingent on its linguistic structure (e.g. things, descriptive words, verbs, also, verb modifiers and so on.). At that point the run base communicated in Table I is utilized to recognize Sentiment Orientation (SO) in the content. The $\mathrm{SO}$ is dictated by recognizing regardless of whether words are commonly autonomous or not. For instance in state "delightful blossom", first word in a diagram is modifier while second is a thing. These two words are commonly needy as communicated in first column of the Subsequent to distinguishing supposition introduction in the content, pre-labelled notion vocabularies are utilized to contrast and Content records to decide slant bearing phrases.

Table 2: Word Context Table

\begin{tabular}{|l|l|l|}
\hline First word & Second word & $\begin{array}{l}\text { Third word } \\
\text { (not extracted) }\end{array}$ \\
\hline Descriptive word & Thing & Anything \\
\hline Verb modifier & Descriptor & Not Noun \\
\hline Descriptive word & Descriptor & Not Noun \\
\hline Thing & Descriptor & Not Noun \\
\hline Verb modifier & Verb & Anything \\
\hline
\end{tabular}

In Social media a few expressions additionally bear Emotions. To decide assessment introduction of Emotions phrases, pre-coded emotions assessments are utilized for instance smiley is coded as positive supposition. Emotions phrases are of higher priority among others i.e., as for feeling bearing expressions. At long last, each expression extremity is joined to decide the possible extremity of a sentence and elements in those sentences.

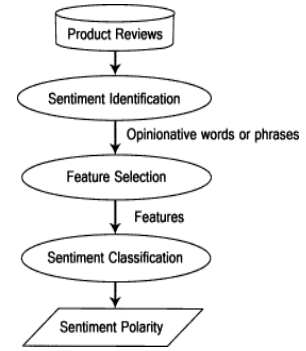

Figure 2: Processing of reviews

To determine that the sentiments of sentences calculated above are associated with which we are using Content-based filtering frameworks are an exceptional sort of data Separating frameworks, Data separating manages the conveyance of things chose from an expansive gathering that the client is probably going to Separating frameworks, Data separating manages the conveyance of things chose from an expansive gathering that the client is probably going to discover intriguing or valuable and can be viewed as an arrangement undertaking. In light of preparing information a client show is initiated that empowers the framework to characterize concealed things into a positive class $\mathrm{c}$ (relevant to the client) or a negative class $\mathrm{c}$ (immaterial to the client). The preparation set comprises of the things that the client discovered intriguing. These things shape preparing examples that all have a property. This trait indicates the class of the thing in light of either the rating of the client or on understood confirmation. Formally, a thing is portrayed as a vector ( ) $\mathrm{n} \mathrm{x}, \mathrm{x} \ldots$ $\mathrm{x}=12$ of $\mathrm{n}$ segments. The segments can have double, ostensible or numerical traits and are gotten from either the substance of the things or from data about the clients' inclinations. The undertaking of the learning technique is to choose a capacity in view of a preparation set of $\mathrm{m}$ input vectors that can characterize anything in the gathering. The capacity $\mathrm{h}(\mathrm{)} \mathrm{X}$ will either have the capacity to characterize a concealed thing as positive or negative without a moment's delay by restoring a double esteem or restore a numerical esteem All things considered a limit can be utilized to decide whether the thing is applicable or superfluous to the client.

\section{Building Sentimental Lexicons}

We consider the inclination embeddings to building suspicion vocabulary image, which is profitable for evaluating how much feeling embeddings improve lexical level assignments that need to find comparability's between words. They present the classification way deal with construct conclusion dictionary by in regards to assumption embeddings as word highlights, and after that portray trial settings and the outcome.

\section{System Architecture}

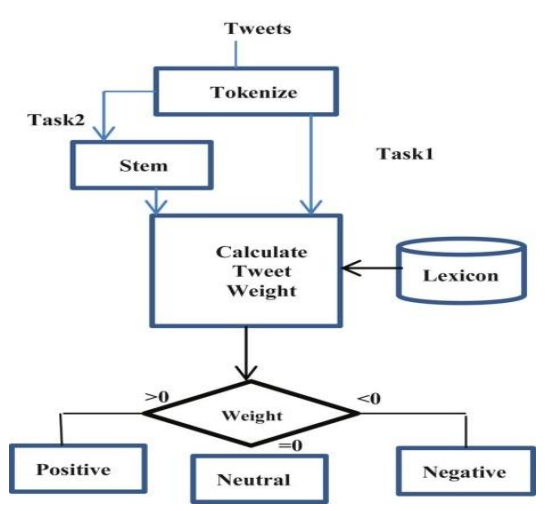




\section{Exploratory Outcomes}

How about we consider the after effects of the characterization of customer audits.framework, customer judgments are utilized. Framework is displayed to open and they were gotten some information about the exactness of this framework. Arrangements of arbitrarily chose posts from client remarks on these posts were gathered. These posts with remarks were given to a set of judges to measure assessment and sentiments in these posts. These presents were arranged in on three classes to be specific positive, negative, and unbiased by the judges. Judges were advised about these classes before on and they have given their input appropriately. Haphazardly 100 post of each class were chosen and exhibited to the framework.

The framework got and investigated posts with remarks what's more, amassed feelings and sentiments delineated in those posts. After this an itemized examination is performed between order of human judges and the framework and results are accounted.

Subsequent to dissecting the outcomes the accompanying theories can be finished up:

\section{- Admin \\ - $\quad$ Retailer (Seller) \\ - Customer}

The administration side work where, in he send the items keeps up the site and furthermore track client stroll through towards the site and catches end customer surveys into stock Database.Item organization includes including new items, refresh item information's, erasing old items from the site and other basic exercises and so forth.The part of head includes a lot of multitasking. You will work with groups, supervise the tasks inside your organization, oversee gatherings, facilitate with administration and participate in arranging as indicated by the necessities of your organization. Overseeing administrative or other regulatory staff.

- $\quad$ Login

- $\quad$ Add Positive \&amp; Negative Words

- View All Register User

- View All Register Seller

- View all vender included Products

- View all client acquired item

- View all conclusion based survey

- All audits check in light of month

The retailer giving an astounding Seller encounter, a Seller Support is required to address framework issues, distinguish and actualize process changes, create interior documentation and add to a group domain, all while clinging to benefit level assertions for telephone, email and talk bolster.

- Enlist(Register)

- Login

- $\quad$ Add items

- View Purchased items

- Logout

Arrangements with respect to discounts, substitution, repair or revise for flawed or harmed items as well as fragmented administrations ought to be clear Products and ventures ought to be given clear data in Arabic and some other dialect notwithstanding showing costs in UAE cash (Dirham) all customers ought to be furnished with a dated nifty gritty receipt. Merchants of utilized or repaired merchandise should mark the item condition obviously and plainly Offer items with substantial assurances and warrantees Administrations suppliers need to ensure benefit quality for a timeframe. On the off chance that administrations are not done with due care, the administration must be given again to free or discounted.[19] Guarantee that a representative learning is good with the scope of items and administrations advertised. A customer part characterizes consents for clients to play out a gathering of undertakings. In a default Word Press establishment there are some predefined parts with a predefined set of consents. These parts are Super Admin, Administrator, Editor, Author, Contributor, and Subscriber.

- Enrol

- Register

- View Products

- View Products Reviews

- Purchase item

- Enter audit

- Logout

Customer profiling is the chief piece of our undertaking which covers the single sign on client and furthermore enlists new client to the web based business website. This includes keeping up clients individual data which is required to send items at an ordained time.

\section{Conclusion}

We assumption particular word encloses (such as presumption encloses) in this survey. Not the same as majority of leaving thinks about that exclusive encode word settings in word enclosing, we factor in evaluation of works to empower the limit of word encloses in getting word resemblances to the extent estimation semantics. Subsequently, the words with comparable settings yet inverse slant extremity names like "great" and "terrible" can be isolated in the estimation implanting space. We acquaint a few neural systems with successfully encode setting and estimation level information at the same time into word embeddings unfriendly.

The adequacy of feeling embeddings are confirmed observationally on three conclusion investigation errands. The conclusion investigation, we demonstrate that supposition embeddings are helpful for finding similitudes between estimation words. In the sentence level conclusion characterization, supposition encloses are useful by catching unfairness highlights for foreseeing the assumption of sentences. On lexical level undertaking like building assumption vocabulary.

\section{References}

[1] Tang D, Wei F, Yang N, Zhou M, Liu T \& Qin B, "Learning sentiment-specific word embedding for twitter sentiment classification", Proceeding of the 52th Annual Meeting of Association for Computational Linguistics, (2014), pp.1555-1565.

[2] Tang D, Wei F, Qin B, Zhou M \& Liu T, "Building largescale twitter-specific sentiment lexicon: A representation learning approach", Proceedings of COLING, the 25th International Conference on Computational Linguistics, (2014), pp.172-182.

[3] Ravi K \& Ravi V, "A survey on opinion mining and sentiment analysis: Tasks, approaches and applications”, Knowl.-Based Syst., Vol.89, (2015), pp.14-46.

[4] Medhat W, Hassan A \& Korashy H, "Sentiment analysis algo rithms and applications: A survey", Ain Shams Eng. J., Vol.5, (2014), pp.1093-1113.

[5] Tang H, Tan S \& Cheng X, "A survey on sentiment detection of reviews", Expert Syst. Appl., Vol.36, No.7, (2009), pp.1076010773.

[6] Yang CS \& Shih HP, "A Rule-Based Approach For Effective Sentiment Analysis", PACIS Proceedings, (2012).

[7] Quan C \& Ren F, "Unsupervised product feature extraction for feature-oriented opinion determination", Inf. Sci., Vol.272, (2014), pp.16-28.

[8] Wu M, Wang L, Li M \& Long H, "An approach of product usability evaluation based on Web mining in feature fatigue analysis", Comput. Ind. Eng., Vol.75, (2014), pp.230-238.

[9] Bucur C, "Using Opinion Mining Techniques in Tourism", Procedia Econ. Finance, Vol.23, (2015), pp.1666-1673.

[10] Montejo-Ráez A, Martínez-Cámara E, Martín-Valdivia MT \& Ureña-López LA, "Ranked Word Net graph for Sentiment Polarity Classification in Twitter", Comput. Speech Lang., Vol.28, No.1, (2014), pp.93-107.

[11] Surendar, A. (2018, January 1). Letter from the desk of editor's. International Journal of Pharmaceutical Research, 10(1). 
[12] García-Pablos A, Cuadros M \& Rigau G, "W2vlda: almost unsupervised system for aspect based sentiment analysis", Expert Systems with Applications, Vol.91, (2018), pp.127-137.

[13] Moilanen K \& Pulman S, "The Good, the Bad, and the Unknown: Morphosyllabic Sentiment Tagging of Unseen Words", Proc. 46th Ann. Meeting of the Assoc. for Computational Linguistics on Human Language Technologies, (2008), pp.109-112.

[14] Read J, "Recognising Affect in Text Using Pointwise Mutual Information", master's thesis, Univ. of Sussex, 2004.

[15] Miller GA, "WordNet: An On-line Lexical Database", Int'l J. Lexicography, special issue, Vol.3, No.4, (1990), pp.235-312.

[16] Andreevskaia A \& Bergler S, "Mining WordNet for Fuzzy Sentiment: Sentiment Tag Extraction from WordNet Glosses", Proc. 11th Conf. European Chapter of the Assoc. for Computational Linguistics, 2006.

[17] Ku LW, Huang TH \& Chen HH, "Using Morphological and Syntactic Structures for Chinese Opinion Analysis", Proc. Int'l Conf. Empirical Methods in Natural Language Processing, (2009), pp.1260-1269.

[18] Izard CE, The Face of Emotion, Appleton-Century-Crofts, (1971).

[19] Villalobos Antúnez, JV (2017). Karl R. Popper, Heráclito y la invención del logos. Un contexto para la Filosofía de las Ciencias Sociales. Opción Vol. 33, Núm. 84. 5-11 